\title{
Variação das características físico-químicas e microbiológicas das sal- mouras empregadas na salga de queijos tipo mussarela durante o período de sua utilização
}

\section{Variation of physical, chemical and microbiological characteristics of brines ap- plied in the salting of mozzarella cheese during the period of utilization}

Luiz Augusto do Amaral", Antonio Nader Filho*, Sebastiāo Timo laria*, Jesus Aparecido Ferro"'

\begin{abstract}
AMARAL, L.A. do et al. Variação das características físico-químicas e microbiológicas das salmouras empregadas na salga de queijos tipo mussarela durante o periodo de sua utilização. Rev. Saúde públ., S. Paulo, 26: 41 - 5, 1992. Foram analisadas 40 amostras de salmouras empregadas na salga por submersão de queijos tipo mussarela, em uma indústria de laticínios do Estado de São Paulo, Brasil, com o objetivo de se conhecer a variação das características físico-químicas e

- hhinlógicas durante o período de sua utilização. Os valores médios do $\mathrm{pH}$, concentração de clorelu un -. to proteínas solúveis, desde o preparo da salmoura até o $21^{\circ}$ dia de utilização, variaram de 7,21 a $\lrcorner, 76,27,1$ a 24,5 e de zeto a $0,126 \mathrm{mg} / \mathrm{ml}$, respectivamente. Por outro lado, os valores médios das contagens de microrganismos mesófilos e do número mais provável de coliformes totais e de origem fecal variaram de $5,8 \times 10 \mathrm{UFC} / \mathrm{ml}$ a $6,9 \times 10^{4} \mathrm{UFC} / \mathrm{ml}$, zero a $1,6 \times 10^{5} / 100 \mathrm{ml}$ e zero a $1,1 \times 10^{5} / 100 \mathrm{ml}$, respectivamente. Além disso, os valores médios das contagens de bolores e leveduras e de Staphylococcus coagulase positiva, variaram de $0,4 \mathrm{x}$ $10 \mathrm{UFC} / \mathrm{ml}$ a $2,0 \times 10^{3} \mathrm{UFC} / \mathrm{ml}$ e de zero a $1,3 \times 10 \mathrm{UFC} / \mathrm{ml}$, respectivamente. Os resultados encontrados sugerem a existência de condições higiênicas inadequadas durante o preparo e utilização das salmouras, de modo a representar uma importante fonte de contaminação para os queijos. Em decorrência deste fato, existe a possibilidade do comprometimento da qualidade dos queijos, de modo a representar risco potencial à população consumidora.
\end{abstract}

Descritores: Higiene dos alimentos. Queijo. Cloreto de Sódio.

\section{Introdução}

Embora ocorram variaçōes especificas entre os processo de fabricação dos diferentes tipos de queijos, de um modo geral tais procedimentos envolvem as fases de seleção e pasteurização do leite, coagulação, corte do coágulo, dessoragem, enformagem, salga, maturação ou não e embalagem (Behmer ${ }^{3}$, 1977).

Durante o processo de fabricação do queijo tipo mussarela, a enformagem é precedida pelo aquecimento da massa a $50^{\circ} \mathrm{C}$ por $20 \mathrm{~min}$, picagem e filagem a $70^{\circ} \mathrm{C}$, fato que caracteriza este

* Departamento de Medicina Veterinária Preventiva da Faculdade de Ciências Agrárias e Veterinárias da Universidade Estadual Paulista - Jaboticabal, SP - Brasil.

** Departamento de Microbiologia do Instituto de Cièncias Biomédicas da Universidade de São Paulo - São Paulo, SP - Brasil.

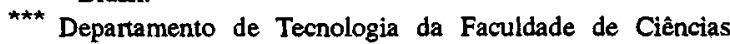
Agrárias e Veterinárias da Universidade Estadual Paulista - Jaboticabal, SP - Brasil.

Separatas/Reprints: L.A. do Amaral - Rodovia Carlos Tonanni - km. 5 - 14870 - Jaboticabal, SP - Brasil.

Publicação financiada pela FAPESP. Processo Saúde Coletiva 91/4994-0. tipo de queijo como sendo de massa cozida. Dentre os diferentes tipos de salga dos queijos, destaca-se a salga por submersão, onde o produto é mantido em salmoura por tempo variável. Para o queijo tipo mussarela esse intervalo de tempo varia de 5 a 10 horas a uma temperatura de $18^{\circ} \mathrm{C}$ (Shegdoni e col. ${ }^{18}, 1979$ ).

A reutilização das salmouras na indústria de queijos representa motivo de preocupação, pois acarreta aumento de impurezas nesta solução, que pode ocasionar modificações em sua composiçāo físico-química (Casalis e col. ${ }^{5}, 1969$ ), de modo a propiciar maior sobrevivência e/ou multiplicaçāo de microrganismos (Lachica ${ }^{11}, 1971$ ).

Mansour e Alais ${ }^{13}$ (1972), estudando salmouras empregadas na salga de queijos, observaram que durante o periodo de sua utilização ocorre queda gradativa dos valores de $\mathrm{pH}$ e da concentração de cloreto de sódio, bem como aumento no teor de proteínas solúveis.

Amaral e col. ${ }^{1}$ verificaram em salmouras empregadas na salga do queijo tipo "Minas" frescal, variações nas determinaçōes de $\mathrm{pH}$, cloreto de sódio e de proteínas solúveis, cujos valores situaramse entre 7,55 e $4,73,15,0 \%$ e $9,1 \%$ e 0,0 e 
$3,756 \mathrm{mg} / \mathrm{ml}$, desde o dia zero até o $21^{\circ}$ dia de utilização respectivamente.

A qualidade microbiológica da água e do sal utilizados no preparo da salmoura assume papel importante, pois a presença de microrganismos pode torná-la importante fonte de contaminação para os queijos. A este respeito, estudos realizados no sal de origem marinha revelaram a presença de microrganismos mesófilos, bolores, leveduras $\mathrm{e}$ bactérias do gênero Clostridium (Ribeiro e col. ${ }^{15}$, 1968; Santiago ${ }^{16}$, 1976; Silva e col. ${ }^{19}$, 1976).

Alguns trabalhos tem evidenciado, também, que durante o período de utilização das salmouras na salga de queijos ocorre aumento gradativo do número de microrganismos mesófilos, bolores e leveduras (Cantoni e col. $\left.{ }^{4}, 1967\right)$, e de bactérias do grupo coliforme (Centeleghe e col. 6 , 1972).

A este respeito, Amaral e col.', estudando as características microbiológicas das salmouras utilizadas na salga de queijos "Minas" frescal, observaram elevados índices de contaminação, cujas contagens de microrganismos mesófilos, coliformes totais, coliformes de origem fecal, Staphylococcus aureus, e de bolores e leveduras atingiram valores da ordem de $2,9 \times 10^{11}, 7,8 \times 10^{12}$, $7,8 \times 10^{12}, 2,3 \times 10^{3}$ e $7,4 \times 10^{5}$, respectivamente.

Apesar da importância que as salmouras utilizadas na salga de queijos podem representar para a qualidade do produto, o Regulamento de Inspeção Industrial e Sanitária de Produtos de Origem Animal ${ }^{14}, 1980$, não estabelece os tipos e números de microrganismos que podem ser tolerados.

Assim, diante do exposto e considerando as escassas informações a esse respeito em nosso meio, idealizou-se o presente trabalho com o objetivo de conhecer as variaçãoes de algumas características físico-químicas e microbiológicas das salmouras utilizadas na salga de queijos tipo mussarela.

\section{Material e Método}

Foram analisadas 5 partidas de salmouras utilizadas no processo de salga por imersão de queijos tipo mussarela, em uma indústria de lacticínios situada no Estado de São Paulo, subordinada à fiscalização do Serviço de Inspeção Federal do Ministério da Agricultura.

\section{Colheita e transporte das amostras de salmoura}

Para cada uma das 5 partidas estudadas, foram colhidas amostras de salmoura logo após o seu preparo, dia zero, assim como no $3^{\circ}, 6^{\circ}, 9^{\circ}$, $12^{\circ}, 15^{\circ}, 18^{\circ}$ e $21^{\circ}$ dias de utilização, de modo a totalizar 40 amostras.
As colheitas foram efetuadas diretamente dos tanques de salga, após a homogeneização das salmouras, sendo utilizados frascos esterilizados com capacidade de $500 \mathrm{ml}$. Em seguida, as amostras foram colocadas em caixa de material isotérmico contendo cubos de gelo e transportadas para o laboratório, onde, imediatamente após a sua chegada, foram realizadas as análises físico-químicas e microbiológicas.

\section{Análises físico-químicas}

As amostras de salmoura foram submetidas às determinações do valor do $\mathrm{pH}$, através da utilização de potenciômetro (pH METER HM-7A), assim como às determinações de proteinas solúveis (Hartree ${ }^{9}, 1972$ ) e das concentraçōes de cloreto de sódio, utilizando-se areômetro Baumé.

\section{Análises microbiológicas}

Para a realização das análises microbiológicas, tomou-se $1 \mathrm{ml}$ da amostra da salmoura e transferiu-se para um tubo de ensaio contendo $9 \mathrm{ml}$ de água peptonada a $0,1 \%$ estéril. A seguir, preparou-se diluições decimais consecutivas até $10^{-5}$ $\left(\right.$ APHA $\left.^{2}, 1976\right)$.

Assim sendo, a contagem de Staphylococcus coagulase positiva e de bolores e leveduras foi efetuada nas diluições até $10^{-3}$; a contagem de microrganismos mesófilos aeróbios ou facultativos viáveis e a determinação do número mais provável de coliformes totais e de origem fecal foram efetuadas em todas as diluições até a $10^{-5}$. As contagens de microrganismos mesófilos aeróbios ou facultativos viáveis foram realizadas em ágar padrão para contagem, após a incubação a $35^{\circ} \mathrm{C}$ por $48 \mathrm{~h}$.

$\mathrm{O}$ número mais provável de coliformes totais foi obtido pela técnica descrita em $\mathrm{APHA}^{2}$, em caldo lauril sulfato, série de 5 tubos; incubação a $35^{\circ} \mathrm{C}$ por $24-48 \mathrm{~h}$; confirmação em caldo lactosebile-verde brilhante a $2 \%$ a $35^{\circ} \mathrm{C}$ por $24-48 \mathrm{~h}$.

A pesquisa de coliformes de origem fecal foi realizada a partir dos tubos positivos de caldo lauril sulfato, usando-se caldo E.C., incubados a $44,5^{\circ} \mathrm{C}$ em banho-maria por $24 \pm 2 \mathrm{~h}$, conforme descrito em APHA ${ }^{2}$.

As contagens de bolores e leveduras foram realizadas em ágar malte adicionado de solução de antibióticos e incubação a $25^{\circ} \mathrm{C}$ por 5 dias.

A contagem de Staphylococcus coagulase positiva foi feita conforme APHA ${ }^{2}$, por semeadura em superfície em ágar Baird-Parker, incubação a $35^{\circ} \mathrm{C}$ por $48 \mathrm{~h}$. As colônias suspeitas foram testadas frente a plasma de coelho para verificar produção de coagulase. 
Tabela 1. Médias aritméticas das análises físicoquímicas de salmouras utilizadas na salga de queijos tipo mussarela, segundo os dias de utilização.

\begin{tabular}{cccc}
\hline & \multicolumn{3}{c}{ Parâmetros físico-químicos } \\
\cline { 2 - 4 } $\begin{array}{c}\text { Dias de } \\
\text { utilizacão }\end{array}$ & $\mathrm{pH}$ & $\mathrm{NaCl} \%$ & $\begin{array}{c}\text { Proteínas } \\
\mathrm{mg} / \mathrm{ml}\end{array}$ \\
\hline 0 & 7,21 & 27,1 & - \\
3 & 6,49 & 26,9 & 0,057 \\
6 & 6,19 & 26,0 & 0,062 \\
9 & 6,18 & 25,7 & 0,064 \\
12 & 5,95 & 25,7 & 0,069 \\
15 & 5,88 & 25,4 & 0,078 \\
18 & 5,87 & 25,0 & 0,086 \\
21 & 5,76 & 24,5 & 0,126 \\
\hline
\end{tabular}

\section{Resultados e Discussão}

A Tabela 1 mostra a distribuição das médias aritméticas dos valores obtidos nas análises físicoquímicas das 5 partidas de salmouras utilizadas na salga de queijo tipo mussarela, segundo os dias de utilização. Verifica-se acentuada redução dos valores médios do $\mathrm{pH}$ no $3^{2}$ dia de utilização das salmouras, fato este também observado por Mansour e Alais ${ }^{13}$ (1972) e Amaral e col. ${ }^{1}$ (1991). Segundo Lacrampe e col. ${ }^{12}$ (1971), a referida redução pode ser atribuída ao aporte inicial de ácido láctico liberado do soro dos queijos durante o processo de salga. A diminuição pouco significativa dos valores médios do $\mathrm{pH}$ observada até o $21^{\circ}$ dia de utilização das salmouras, também constatada por Mansour e Alais ${ }^{13}$ (1972) e Amaral e col. ${ }^{1}$, pode ser justificada pela capacidade tamponante da caseína incorporada às salmouras durante o período de utilização (Clark e col. $^{7}$, 1983).

Os dados constantes da Tabela 1 evidenciam, ainda, que as médias aritméticas dos valores das concentrações de cloreto de sódio apresentaram uma redução de $2,6 \%$ do valor inicial ao longo dos 21 dias de utilização das salmouras. Amaral e col. (1991), analisando amostras de salmouras utiliza- das na salga de queijos "Minas" frescal, constataram que a redução dos valores médios do cloreto de sódio foi da ordem de $39,3 \%$. Segundo Casalis e col. ${ }^{5}$ (1969), a redução da concentração de cloreto de sódio nas salmouras decorre da diluição da solução através do soro liberado pelos queijos e da penetração do sal no interior deste produto, durante o processo de salga.

A Tabela 1 mostra, também, que as médias aritméticas dos valores das concentraçōes de proteínas solúveis apresentaram uma elevação gradativa no decorrer da utilização das salmouras, chegando a atingir $0,126 \mathrm{mg} / \mathrm{ml} \mathrm{no} 21^{\circ}$ dia. Amaral e col. ${ }^{1}$ (1991), investigando amostras de salmouras utilizadas na salga de queijo "Minas" frescal, constataram, também, um aumento dos valores das concentrações de proteínas solúveis. Todavia, a concentração média dessas proteínas atingiu um valor muito superior, ou seja, $3,756 \mathrm{mg} / \mathrm{ml}$. Segundo Casalis e col. ${ }^{5}$, (1969), tais variaçōes podem ser atribuídas à presença de proteínas liberadas no soro dos queijos e/ou fragmentos de queijos desprendidos durante o processo de salga.

$\mathrm{Na}$ Tabela 2 encontram-se as médias geométricas das contagens de microrganismos das 5 partidas de salmouras utilizadas na salga de queijo tipo mussarela, segundo os dias de utilização. Observa-se que os valores médios das contagens de microrganismos mesófilos variaram de $5,8 \times 10$ $\mathrm{UFC} / \mathrm{ml}$ a $6,9 \times 10^{4} \mathrm{UFC} / \mathrm{ml}$ do dia zero ao $21^{2}$ dia de utilização das salmouras. Estudos realizados por Amaral e col. ${ }^{1}$ (1991), em salmouras utilizadas na salga de queijo "Minas" frescal, revelaram resultados que variaram de $2,1 \times 10^{2} \mathrm{UFC} / \mathrm{ml}$ a 2,9 $x 10^{11} \mathrm{UFC} / \mathrm{ml}$. A presença de microrganismos mesófilos no dia zero, ou seja, antes da utilização das salmouras, pode ser devido à água e ao próprio sal utilizados na sua preparação (Ribeiro e col. ${ }^{15}$, 1968; Santiago $\left.{ }^{16}, 1977\right)$.

O aumento do número de microrganismos mesófilos, durante a utilização das salmouras na salga de queijos tipo mussarela, provavelmente não seja devido à multiplicação desses microrganismos já

Tabela 2. Médias geométricas das análises microbiológicas das salmouras utilizadas na salga de queijos tipo mussarela segundo os dias de utilização

\begin{tabular}{cccccc}
\hline $\begin{array}{c}\text { Dias de } \\
\text { utilização }\end{array}$ & $\begin{array}{c}\text { Mesofilos } \\
(\text { UFC/mI) }\end{array}$ & $\begin{array}{c}\text { Coliformes totais } \\
\text { (NMP/100ml) }\end{array}$ & $\begin{array}{c}\text { Coliformes de } \\
\text { origem fecal } \\
\text { (NMP/100ml) }\end{array}$ & $\begin{array}{c}\text { Bolores e } \\
\text { leveduras } \\
\text { (UFC/ml) }\end{array}$ & $\begin{array}{c}\text { S. coagulase }+ \\
\text { (UFC/mI) }\end{array}$ \\
\hline 0 & $5,8 \times 10$ & $-(1)$ & - & $0,4 \times 10$ & - \\
3 & $6,1 \times 10^{4}$ & $2,3 \times 10^{3}$ & $1,7 \times 10^{3}$ & $4,2 \times 10^{2}$ & $1,1 \times 10$ \\
6 & $6,2 \times 10^{4}$ & $4,6 \times 10^{4}$ & $4,4 \times 10^{4}$ & $1,6 \times 10^{3}$ & - \\
9 & $3,2 \times 10^{4}$ & $1,5 \times 10^{4}$ & $1,5 \times 10^{4}$ & $1,8 \times 10^{3}$ & $1,2 \times 10$ \\
12 & $6,5 \times 10^{4}$ & $3,8 \times 10^{4}$ & $3,3 \times 10^{4}$ & $1,4 \times 10^{3}$ & - \\
15 & $5,5 \times 10^{4}$ & $7,2 \times 10^{4}$ & $7,2 \times 10^{4}$ & $1,3 \times 10^{3}$ & $0,3 \times 10$ \\
18 & $6,4 \times 10^{4}$ & $1,6 \times 10^{5}$ & $1,2 \times 10^{5}$ & $2,0 \times 10^{3}$ & $0,4 \times 10$ \\
21 & $6,9 \times 10^{4}$ & $1,6 \times 10^{5}$ & $1,1 \times 10^{5}$ & $2,0 \times 10^{3}$ & $1,2 \times 10$ \\
\hline
\end{tabular}

(1) não foram encontrados microrganismos viáveis em nenhuma das amostras analisadas. 
que o meio não apresenta características ideais para que esse fato aconteça (Jay ${ }^{10}, 1978$; Sperber $\left.^{20}, 1983\right)$, e sim à transferência desses microrganismos dos queijos para as salmouras. Tais microrganismos estão presentes no queijo devido à má qualidade da matéria-prima ou má condiçōes de higiene durante sua fabricação (Santos ${ }^{17}, 1965$ ). Sabe-se, também, que os microrganismos mesófilos provenientes do próprio fermento lácteo utilizado no processamento do queijo podem ser transferidos para as salmouras (Shegdoni e col. ${ }^{18}, 1979$ ).

No que se refere a bactérias coliformes totais e de origem fecal observa-se, ainda na Tabela 2, que os valores médios dos NMP dessas bactérias variaram de zero a $1,6 \times 10^{5} / 100 \mathrm{ml}$ e de zero a $1,1 \times 10^{5} / 100 \mathrm{ml}$, do dia zero ao $21^{8}$ dia de utilização, respectivamente. Estudos realizados por Amaral e col. ${ }^{\prime}$ (1991), com salmouras utilizadas na salga de queijos "Minas" frescal, evidenciaram variações médias no NMP dessas bactérias de zero a $7,8 \times 10^{2} / 100 \mathrm{ml}$, durante o mesmo periodo de utilização. A contaminação de salmouras por bactérias coliformes totais e de origem fecal foi verificada, também, por Viard \& Deveau ${ }^{21}$ (1972) e Dempster e col. ${ }^{8}$ (1973). A presença dessas bactérias nas salmouras pode ser devida à transferência desses microrganismos dos queijos às salmouras $e$ à contaminação decorrente da constante manipulação que os queijos são submetidos durante o processo de salga.

A Tabela 2 mostra, ainda, a presença nas salmouras de bolores e leveduras cujos números médios variaram de $0,4 \times 10 \mathrm{UFC} / \mathrm{ml}$ a $2,0 \times 10^{3}$ $\mathrm{UFC} / \mathrm{ml}$, nos dias zero e $21^{\circ}$ de utilização das salmouras, respectivamente. Amaral e col. ${ }^{1}$ (1991), obtiveram para salmouras utilizadas na salga de queijos "Minas" frescal, durante o mesmo periodo de utilização, valores médios desses microrganismos que variaram de $1,2 \times 10^{2} \mathrm{UFC} / \mathrm{ml}$ a $2,4 \times 10^{6}$ UFC/ml. Segundo Santiago ${ }^{16}$ (1976), a contaminação das salmouras por esses microrganismos, antes da sua utilização, pode ser devido à presença desses microrganismos no sal utilizado; entretanto, o próprio equipamento e o ambiente podem contribuir para a presença desses microrganismos na salmoura.

Observa-se também na Tabela 2 a contaminação das salmouras por Staphylococcus coagulase positiva, cujos números médios variaram de zero a $1,2 \times 10 \mathrm{UFC} / \mathrm{ml}$. Em trabalho realizado com salmoura utilizada na salga de queijos "Minas" frescal, Amaral e col. (1991) obtiveram números médios para esses microrganismos que variaram de zero a $2,3 \times 10^{3} \mathrm{UFC} / \mathrm{ml}$. A presença desses microrganismos nas salmouras pode estar relacionada à manipulação a que são submetidos os queijos e à transferência dos mesmos dos queijos a salmouras, durante o processo de salga. A presença de Staphylococcus coagulase positiva nas salmouras pode acarretar a contaminação de partidas de queijos, e havendo cepas produtoras de enterotoxinas, pode, embora potencialmente, representar riscos de saúde aos consumidores.

Os menores valores médios das concentraçōes de cloreto de sódio e de proteínas solúveis observados na Tabela 1, quando comparados aos obtidos por Amaral e col. ${ }^{1}$ (1991), talvez possam ser atribuídos ao fato do queijo tipo mussarela apresentar maior consistência do que o "Minas" frescal, o que dificultaria a troca de elementos entre o queijo e a salmoura. Acredita-se, também, que tais diferenças possam ser atribuídas a menor quantidade de queijo tipo mussarela produzida durante a realização do presente trabalho. Os valores médios das contagens dos microrganismos pesquisados verificados na Tabela 2 apresentam-se menores do que os encontrados por Amaral e col. ${ }^{1}$ (1991), para salmouras utilizadas na salga de queijo "Minas" frescal. Este fato pode ser devido aos fatores relacionados anteriormente, associado ao cozimento que a massa do queijo tipo mussarela sofre durante o processo de fabricação.

Os achados obtidos, analisados e discutidos no presente trabalho, evidenciam as precárias condições de higiene no preparo e utilização das salmouras utilizadas na salga do queijo tipo mussarela, de modo a representar uma importante fonte de contaminação para este produto. Assim sendo, acredita-se que possa ocorrer o comprometimento da qualidade microbiológica do queijo tipo mussarela oferecido ao consumo, de modo a representar risco potencial para a saúde da população consumidora.

AMARAL, L.A. do et al. [Variation of physical, chemical and microbiological characteristics of brines applied in the salting of mozzarella cheese during the period of utilization]. Rev. Saúde públ., S. Paulo, 26: 41 - 5, 1992. Variation of the physical, chemical and microbiological characteristics of brines during their utilization for salting mozzarella cheese. Forty brine samples used for submersion salting of mozzarella cheese in a dairy industry in the State of S. Paulo, Brazil, were analysed for the purpose of discovering the variation in the physical, chemical and microbiological characteristics observed over their period of utilization. The mean values preparation up to the 21st day of utilization of $\mathrm{pH}$, sodium chloride and protein concentration varied from 7.21 to 5.76 , from 27.1 to 24.5 and from zero to 0.126 $\mathrm{mg} / \mathrm{ml}$, respectively over the period from their. The mean values of the mesophylic microorganism counts and of the total and fecal coliforms MPN varied from $5.8 \times 10 \mathrm{CFU} / \mathrm{ml}$ to $6.9 \times 10^{4} \mathrm{CFU} / \mathrm{ml}$, from zero to $1.6 \times 10^{5} / 100 \mathrm{ml}$ and from zero to $1.1 \times 10^{5} / 100 \mathrm{ml}$, respectively. Moreover, the mean values of mould and yeast and Staphylococcus 
positive coagulase counts varied from $0.4 \times 10$ $\mathrm{CFU} / \mathrm{ml}$ to $2.0 \times 10^{3} \mathrm{CFU} / \mathrm{ml}$ and from zero to 1.3 $x 10 \mathrm{CFU} / \mathrm{ml}$, respectively. The results obtained suggest that the hygienic conditions during the preparation and the utilization of the brine were not satisfactory so that they may represent an important source of contamination for the cheeses. The quality of the product may be harmed, as a result of this fact, in such a way as to represent a potential harzard for the health of the consuming population.

Keywords: Food hygiene. Cheese. Sodium Chloride.

\section{Referências Bibliográficas}

1. AMARAL, L.A.; IARIA, S.T.; NADER FILHO, A. Variação das características físico-químicas e microbiológicas das salmouras empregadas na salga de queijos tipo Minas frescal durante o periodo de sua utilização. Rev. Microbiol., 22: 136-40, 1991.

2. AMERICAN PUBLIC HEALTH ASSOCIATION. Committee on Microbiological Methods for Foods. Compendium of methods for the microbiological examination of foods. Washington, D.C., 1976.

3. BEHMER, M.L.A. Tecnologia do leite. 7a ed. São Paulo, Nobel, 1977.

4. CANTONI, C.; MOLNAR, M.R.; RENON, P.; CALCINARDI, C. Ricerche sulla microbiologie e la composizione chimica delle salamoie di coppe. Arch. Vet. ital., 18 (1/2): 61-78, 1967.

5. CASALIS, J.; LUQUET, F.M.; ROSSIER, F. Sur le traitement des saumures de fromagerie par les rayons ultraviolets. Le Lait, (483 484): 134-45, 1969.

6. CENTELEGHE; J.L.; MILLIERE; J.B.; WEBER, F. (1971) apud VIARD, M.; DEVEAU, J. Epuration chimique et sterilization microbiologique par traitement thermique des saumures utiliseés dans l'industrie fromage. Le Lait, (511/512): 21-7, 1972.

7. CLARK, D.A.; THOMPSON, J.E.; ROKAHR, J.E. The buffering capacity of bovine milk proteins. Dairy Sci. Abstr., 45: 690, 1983.

8. DEMPSTER, J.F; REID, S.N.; CODY, O. Sources of contamination of cooked, ready-to-eat cured and uncured meats. J. Hyg., 71: 815-23, 1973.

9. HARTREE, E.F. Determination of protein: a modification of the Lowry method the gives a linear photometric response. Anal. Biochem., 48: 422-7, 1972.
10. JAY, J.M. Modern food microbiology. New York, Van Nostrand Reinhold Company, 1978.

11. LACHICA, R.V.F. Metachromatic agar diffusion methods for detecting staphylococcal nuclease activity. Appl. Microbiol., 21: 585-7, 1971.

12. LACRAMPE; J.L.; HARDY, J.; RAMET, J.P.; WEBER, F. Contribution à l'étude de l'évolution chimique et du traitement des saumures de fromagerie. Le Lait, (503/504): 158-75, 1971.

13. MANSOUR, A. \& ALAIS, C. Etude du salage et de l'affinage du fromage en saumure. Le Lait, (519/520): 624-53, 1972.

14. REGULAMENTO de Inspeção Industrial e Sanitária de Produtos de Origem Animal. Decreto $\mathrm{n}^{2} 30.691$ de 29 de março de 1952, alterado pelo Decreto $n^{2} 1255$ de 25 de junho de 1962. Brasilia, Divisão de Inspeção de Produtos de Origem Animal do Ministério da Agricultura, 1980.

15. RIBEIRO, A.M.R.; STOCKER, M.Z.; TROPA, E. Flore bacterienne du sel Portugais son importance pour les industries de conserves alimentaires. Ann. Inst. Pasteur- Lille, 19: 191-204, 1968.

16. SANTIAGO, O. (1976) apud OLIVEIRA, L.A.T. Análise microbiológica do sal empregado na elaboração do charque. Niteroi, 1977. [Dissertação de Mestrado. Universidade Federal Fluminense]

17. SANTOS, D.S. O sal na indústria de lacticínios. Bol. Leite, (441): 1-9, 1965.

18. SHEGDONI, A.; RETTI, C.; SOUZA, G.P. Fabricação de mussarela. Rev. Inst. Lact. Candido Tostes, 34: 27-30, 1979.

19. SILVA, N.M.P.; ERNANDEZ, D.; PEREIRA, L.A.; ALVES, F.C. Estudo microbiológico do sal (cloreto de sódio) de origem marinha. Mem. Inst. Oswaldo Cruz 74: 9-22, 1976.

20. SPERBER, W.H. Influence of water activity on foodbome bacterial: a review. J. Food Protec., 46: 142-50, 1983.

21. VIARD, M. \& DEVEAU, J. Epuration chimique et stérilisation microbiologique par traitement thermique des saumures utilisées dans l'industrie alimentaire et en particular dans l'industrie fromagére. Le Laiţ (511/512): 21-7, 1972.
Recebido para publicação em 17/4/1991

Reapresentado em 11/9/1991

Aprovado para publicação em 5/11/1991 